\title{
The role of gesture duration in the initial unstressed vowel shift in Galician. A first approximation
}

\author{
Alba Aguete Cajiao \\ Instituto da Lingua Galega (Universidade de Santiago de Compostela) \\ alba.aguete@usc.es
}

Submitted: 10/04/2015. Accepted: 15/07/2015. Available on line: 25/05/2016

Citation / Cómo citar este artículo: Aguete Cajiao, A. The role of gesture duration in the initial unstressed vowel shift in Galician. A first approximation . Loquens, 2(2), e022. doi: http://dx.doi.org/10.3989/loquens.2015.022

\begin{abstract}
This study examines a change in the Galician vowel system. This change has been described as the phonologization of the distinction between low-mid-low and mid-high vowels of Galician in unstressed pretonic position. The principal aim of this study is to test whether this distinction can be triggered by the longer duration of those initial vowels, favoured by the structure of the syllable and by the initial prosodic position. To verify this hypothesis, an articulatory simulation study with TADA and an acoustic study with native speakers of Galician were carried out. Since there are no studies in which the unstressed (neither initial nor medial) vowel system of Galician is examined in terms of acoustical properties, the first step was to determine whether it differs from the stressed vowel system and whether there is an acoustical opposition between mid-low and mid-high vowels in initial position. The results showed that there are significant differences between vowels in unstressed syllable and vowels in stressed syllable and also between the unstressed initial vowels $/ \mathrm{e} / \mathrm{and} / \varepsilon / \mathrm{e}$, and $/ \mathrm{o} / \mathrm{and} / \mathrm{o} /$. A linear relation between duration of the gesture and degree of distance between $/ \mathrm{o} /$ and $/ \mathrm{o} /$ and between $/ \mathrm{e} /$ and $/ \varepsilon /$ was found in the simulation study with TADA, and a significant relation between duration and height was found for $/ \mathrm{s} /$ in the acoustic study.
\end{abstract}

Keywords: Galician; vowel height; language change; Galician vowel shift.

RESUMEN: Importancia de la duración gestual en el cambio de las vocales iniciales átonas del gallego: una primera aproximación.- Este estudio examina un cambio producido en el vocalismo gallego. Este cambio ha sido descrito recientemente como la fonologización de la distinción entre las vocales medias-bajas y mediasaltas del gallego en posición átona pretónica. El objetivo principal de este estudio es comprobar si esta distinción puede ser debida a una mayor duración de las vocales en inicio de palabra, propiciada por la estructura de la sílaba y por la posición de inicio de límite prosódico. Con el fin de comprobar la hipótesis, se realizaron un estudio de simulación articulatoria con TADA y un estudio acústico con hablantes nativos de gallego. Dado que no hay estudios en los que se examine el sistema átono del gallego (inicial ni medial) desde una perspectiva acústica, el primer paso ha sido determinar si este difiere del sistema tónico, y comprobar si efectivamente hay una oposición entre las vocales medias-bajas y las vocales medias-altas en posición inicial. Los resultados mostraron que hay diferencias significativas entre vocales en sílaba átona y vocales en sílaba tónica, y también entre las vocales medias-bajas y medias-altas $/ \mathrm{e} / \mathrm{y} / \varepsilon /, \mathrm{y} / \mathrm{o} / \mathrm{y} / \mathrm{o} /$ en posición átona inicial. Se encontró una relación lineal significativa entre la duración del gesto y la mayor distancia entre $/ 0 / \mathrm{y} / 0 / \mathrm{y}$ entre $/ \mathrm{e} / \mathrm{y} / \varepsilon /$ en el estudio de simulación con TADA y, además, una relación significativa entre la duración y la apertura de / / / en el estudio acústico.

Palabras clave: gallego; altura vocálica; cambio lingüístico; cambio en el vocalismo gallego. 


\section{INTRODUCTION}

\subsection{Galician unstressed vowel system}

Historically, the unstressed vowel system of Galician consists of units resulting from neutralization of the opposition between mid-low and mid-high vowels described by Veiga Arias (1965): "el gallego distingue entre /e/ (abierta)-/ẹ/ (cerrada) y /ọ/ (abierta)-/ọ/ (cerrada) solamente en las sílabas acentuadas, pero no en las demás, en las que consiguientemente hay una neutralización"(p. 397). ${ }^{1}$ This neutralization had already taken place in Proto-Ibero-Romance, as Emiliano (2009) observes: "as sete vogais do latim vulgar tardio - [i], [e], [ع], [a], [0], [o], e [u] — se reduziram no proto-ibero-romance em posição átona não final a cinco - [i], [e], [a], [o], e [u] — e em posição final a três $-[\mathrm{e}]$, [a], e [o]" (p. 260). ${ }^{2}$

This differs from the stressed system, where the opposition between $/ \varepsilon /$ and $/ \mathrm{e} /$, and between $/ \mathrm{s} /$ and $/ \mathrm{o} /$, remained in Vulgar Latin and continued into Galician (Lausberg, 1971, p. 253). The neutralization in the unstressed vowel system is confirmed by a comparison with the results in neighbouring languages where the development of unstressed vowels differs from that of the corresponding stressed vowels, e.g., Latin FĚRRUM produced Spanish hierro ['jero], with diphthongization of $\breve{e}$ in stressed position, and Latin PǑRTA produced Spanish puerta ['puerta], but the derivative FĚRRĀRILUs became herrero [e'rero], and PǑRTĀRǏUs produced portero [por'tero]. In both Spanish unstressed instances, we might have expected diphthongization of $\breve{e}$ or $\breve{o}$, as occurred in stressed syllables, if their quality had been preserved in Vulgar Latin.

However, a more recent modification of the unstressed vowel system has been described. Santamarina (1974) was the first to suggest the existence of two different systems in present-day Galician: "uno, antiguo, en el que operaba la neutralización; otro, moderno, en el cual la neutralización ya no opera" (p. 12). ${ }^{3}$ Other authors such as Porto Dapena (1977), Taboada (1979) and more recently Regueira $(2008,2009,2010)$ support Santamarina's view.

This change in the pretonic $\mathrm{c}^{4}$ system is also related to the inflection of verbs. In the "old" system referred to by Santamarina (1974), there is alternation in verbs with an open root vowel (e.g., eu voto ['ew 'boto], "I vote") between the forms in the paradigm where the root vowel is stressed (in which case the mid-low quality of the vowel is maintained) and those where the root vowel is unstressed, in which raising of the root vowel occurs (e.g., nós votamos ['nos bo'tamos] "we vote"). In contrast to this traditional pattern, the new pattern described by Santamarina is characterized by the absence of these vowel alternations in many such verbs, so that the mid-low root vowel is kept throughout the paradigm here (e.g., eu voto ['ew 'boto] "I vote", nós votamos ['nos bo'tamos] "we vote"), and verbs with a mid-high root vowel keep it throughout their paradigm, thereby giving rise to minimal pairs in pretonic position such as for example nós votamos ['nos bo'tamos] "we vote" versus nós botamos ['nos bo'tamos] "we throw". This change in the system of unstressed vowels is also apparent in the way that new derived words are formed because "os derivados que se forman novos sobre palabras con vogal tónica media baixa manteñen a vogal na posición pretónica"5 (Regueira, 2009 , p. 152), as in rosa $\sim$ roseira ['rosa $\sim$ ro'sejra], taberna $\sim$ taberneiro [ta' $\beta \varepsilon \mathrm{sna} \sim$ ta $\beta \varepsilon$ c' neiro] or porta $\sim$ porteiro ['porta por' tejro] (Regueira, 2008).

Regueira (2008), from an Optimality Theory perspective, attributes this change to "un ascenso na xerarquía das constricións de Fidelidade (que obrigarían a que a raíz dos derivados fose 'fiel' á raíz da palabra primitiva) en detrimento das que prefiren vogais medias altas en sílabas átonas" (p. 278). ${ }^{6}$ According to this idea, "os falantes máis conservadores antepoñen o proceso de elevación das vogais átonas á fidelidade á base léxica, mentres que nos falantes mais innovadores a fidelidade é prioritaria, e o proceso de elevación xa non actúa"7 (Regueira, 2010, p. 21). However, this fails to account for the production of unstressed word-initial mid vowels as mid-low, a recent innovation (generally occurring in high-register words), such as in omitir [omi'tic] or emitir [عmi'tir], which contrasts with the realization of word-initial mid vowels in traditional words such as ovella [o'ßeאa] (Regueira, 2010, p. 19).

Thirty years earlier, Porto Dapena $(1977$, p. 19) pointed out that the height of unstressed vowels depends crucially on the structure of the syllable they are part of. Porto Dapena (1977) distinguishes three different conditions affecting the realization of unstressed mid vowels in Galician:

1) En posición inicial absoluta y no trabada, tanto e como o tienden a hacerse abiertas [...] 2) También se pronuncian abiertas en posición inicial absoluta,

\footnotetext{
1 "Galician distinguishes between /ę/ (open) and /ẹ/ (close), and between /Q/ (open) and /ọ/ (close), only in stressed syllables but not in the others, where there is thus neutralization."

2 "The seven vowels of late Vulgar Latin- $[\mathrm{i}],[\mathrm{e}],[\varepsilon],[\mathrm{a}],[0],[\mathrm{o}]$ and $[\mathrm{u}]$ - were reduced in Proto-Ibero-Romance in unstressed non-final position to five- - $[\mathrm{i}],[\mathrm{e}],[\mathrm{a}],[\mathrm{o}]$ and $[\mathrm{u}]$ — and in final position to three: [e], [a] and [o]."

3 "An old one in which neutralization took place, and a modern one where neutralization no longer takes place."

4 We are using the term pretonic in a loose sense to refer to any syllable preceding the stressed one.

5 "New forms derived from words with a mid-low stressed vowel keep the vowel in pretonic position."

6 "A rise in the constraint hierarchy of strict domination (which would require the root of derivatives to remain 'faithful' to the root of the etymon) to the detriment of those that prefer mid-high vowels in unstressed syllables."

7 "More conservative speakers give priority to the raising of unstressed vowels over fidelity to the lexical base, whereas in more innovative speakers fidelity takes precedence, and raising is no longer applied."
} 
cuando van trabadas por una consonante que no sea $n, m$, s o x, y en interior de palabra $[\ldots] 3)[\ldots]$ estas vocales se pronuncian cerradas en todos los demás casos [...]. (pp. 20-21)

Taboada (1979) adds that the quality of unstressed vowels is much more unclear and variable than that of stressed vowels, a phenomenon that he relates to a decrease in articulatory strength. The ideas expressed by Porto Dapena and Taboada are fundamental to our study, where we will look at the position of the syllable as a possible factor triggering the aforementioned change.

In the present study we will focus our attention on unstressed vowels in word-initial position in high-register words newly introduced in Galician, for which there seems to be no lexical conditioning, and which some scholars, notably Regueira (2009), treat as a special group in the change in the system of non-final unstressed vowels.

\subsection{Proposal}

The aim of this study is to take the ideas suggested by Taboada (1979) and Porto Dapena (1977) further by looking at the syllable as the principal factor involved in the new opposition between $/ \mathrm{e} /$ and $/ \varepsilon /$ and between $/ \mathrm{o} /$ and $/ \mathrm{J} /$ in word-initial position, from the point of view of Articulatory Phonology.

In Articulatory Phonology theory, articulatory gestures are the smallest units, the phonological atoms of speech. Gestures are defined as constriction units of action of the articulators, related to an ideal abstract target, but as mental units they are discrete and invariant (Hawkins, 1992, p. 13). Since gestures are naturally dynamical, context-dependent variation and coarticulation are inherent to them, so some parameters such as stiffness and duration of the articulatory gesture may be phonologically constrastive. As Browman and Goldstein pointed out (1993), "a time varying pattern of articulation motion (and its resulting acoustic consequences) is lawfully entailed by the dynamical systems themselves - they are self-implementing" (p. 54). This means that the duration of a gesture may be a distinctive feature, and also that surface alternation may be accounted for by the constriction degree and the dynamical consequences of interaction between the invariant gestural target and the variable duration of the gesture.

According to this theory, neutralizations are the consequence of the coordination of individual gestures in gesture constellations. For example, nasalization of a vowel that is followed by a nasal segment may occur because the timing of activation of the velum aperture ges- ture overlaps with the timing of the tongue body gesture, giving rise acoustically to a nasalized vowel. Similarly, it is not the quality of the vowel that changes but the timing of activation of the gesture for the vowel and the following gesture.

Our hypothesis is that the modification of the Galician unstressed vowel system in word-initial position is triggered by an increase of duration related to the articulatory gesture for the vowel, since greater duration allows for the existence of different ideal targets for mid-low and mid-high vowels. In turn, this increase in the duration of the gesture may be triggered by the particular syllable type, without onset nor coda and in word-initial position, described above for this phenomenon. As Goldstein, Chitoran and Selkirk (2007) say, syllable structure may lead to an increase of gesture duration which has acoustic consequences, since the articulator has more time to reach its ideal target.

Two experiments were performed to test our hypothesis. In the first experiment we tested whether there is a relationship between the duration of the gesture and the acoustic quality of mid vowels in Galician, by modifying, with Task Dynamics Application (TADA), the parameter of duration of gestures involved in the realization of the four Galician mid vowels: / $/$ /, /e/, / / / and /o/.

The second experiment is an acoustic one where we analyzed both mid-low and mid-high vowels in Galician in unstressed and stressed positions produced by native Galician speakers in order to compare the results with those obtained in the first experiment using articulatory synthesis.

\section{GESTURAL SIMULATION STUDY}

\subsection{The Task Dynamics Model}

In order to test the theoretical assumptions of Articulatory Phonology, a computational system called Task Dynamics Application (TADA) was developed by Haskins Laboratories (2001-2006) which runs into MATLAB. TADA is based on the Task Dynamics Model explained by Hawkins (1992):

Task dynamics is a general model of skilled movement control that was developed originally to explain nonspeech tasks such as reading and standing upright, and has more recently been applied to speech. It is based on biological and physical principles of coordinated movement, but is couched in dynamical rather than anatomical or physiological terms. . . Task dynamics describes movement in term of the tasks to be done, and the dynamics involved in doing them. (p. 9)

\footnotetext{
8 " 1 ) in absolute initial position without a coda, both $e$ and $o$ tend to be realized as open. . . 2) They are also pronounced open in absolute initial position when followed in the same syllable by a consonant other than $n, m, s$ or $x$, and within a word. . . 3) . . these vowels are pronounced close in all other cases."
} 
TADA incorporates three interrelated models. In the first, the system generates a coupling graph from an orthographic input introduced by the user. This graph specifies the gestures involved in the realization of the input and the synchronization links between them. The second model generates a gestural score, in which activation timings for each gesture are established. The third model recreates the movements in the vocal tract in the utterance, in a sagittal plane, and generates the acoustic output related to the current input.

Every gesture is specified by Constriction Degree, Constriction Location and Stiffness, in such a way that every modification in the parameters associated with the gesture will give rise to a different gestural score and, as a result, a different output, since any modification in the duration of a given gesture will result in a different coupling between that gesture and the next one.

\subsection{Method for Galician mid vowels}

In this first experiment we try to verify whether there is a relation between vowel height and duration of the gesture. For this purpose, we generated an input to TADA for each Galician mid vowel $(/ \varepsilon /, / \mathrm{e} /, / \mathrm{o} /$ and $/ \mathrm{o} /)$. The words chosen as inputs to the model were emitir and omitir. These words were chosen because they exist in Galician and were also the tokens used in the acoustic experiment (see Section 3.). For each word we introduced two different inputs, one in which the constriction degree for the initial vowel had a mid-low target, and another in which it had a mid-high target. The resulting set of inputs were /emi'tir/ and / $\mathrm{cmi}$ 'tir/ for the midfront vowels, and /omi'tir/ and /omi'tir/ for the mid-back vowels. From every input, TADA generates the gestural score, with the specific activation timing for every gesture and their dynamical parameters. Once those inputs were created, the durations of the tongue body gestures for $/ \mathrm{e} /$ and $/ \varepsilon /$ and the durations of the tongue body and lip aperture gestures for $/ \mathrm{o} /$ and $/ \mathrm{o} /$ were modified, from 10 to $45 \mathrm{~ms}$ in steps of $5 \mathrm{~ms}$.

For every input entered, an acoustic output is produced from the gestural score; for this, TADA uses the synthesizer HLSync, as explained in the manual: "from the area functions, formant resonance frequencies and bandwidths are calculated, and these are used to generate an acoustic waveform using a fixed voiced source" (Nam \& Goldstein, 2007, p. 4). Thus, a different acoustic output for every modification was generated by TADA, meaning that 8 different outputs were generated per vowel, that is, 32 outputs in total.

These acoustic signals (outputs) were analyzed with Praat (Version 5.3.51). Values of $f_{1}, f_{2}$ and duration for every vowel were taken into account. Both $f_{1}$ and $f_{2}$ were measured at the middle of the vowel, since this part is less influenced by transitions.

In order to test our hypothesis that greater duration of the gesture is related to a greater acoustical distinction of the height of mid vowels of Galician, two statistical analyses were carried out. One of these was a Regression Analysis for both $f_{1}$ and $f_{2}$ separately for each vowel. This analysis will reveal if there is a correlation between duration and formant frequencies. Since vowel quality in Galician is delimited by the distance between $f_{1}$ and $f_{2}$, a Regression Analysis for distance between these formant values for the pairs $/ \mathrm{e} /-/ \varepsilon /$ and $/ \mathrm{o} /-/ \mathrm{J} /$ was also performed. Distance was calculated using the Euclidean distance equation. Every Regression was analyzed using SPSS Statistics 20.

\subsection{Results}

The scatterplot in Figure 1 shows $f_{1}$ and $f_{2}$ values for every vowel generated with TADA. All vowels are more centralized at shorter durations. It is even possible to trace the trajectories for every vowel from the centre of the acoustical space (trapezoid) at shorter durations to the edges of the trapezoid at greater durations of the gesture. These centralized vowels at $15 \mathrm{~ms}$ may be due to the fact that the synthesizer model starts out from the neutral position of the tongue, that is, the position for schwa [ə].

For $f$ the scatterplot shows that the trajectories seem to delineate a movement from maximum aperture towards closure for every vowel as the duration of the gesture increases. There is more dispersion of $f_{1}$ for mid-high vowels than for mid-low vowels. Formant values of $/ \mathrm{e} /{ }_{15 \mathrm{~ms}}, / \mathrm{e} /{ }_{20 \mathrm{~ms}}$ and $/ \mathrm{e} /{ }_{40 \mathrm{~ms}}$ interfere noticeably with those of $/ \varepsilon /$.

Figure 1: Scatterplot of $f_{1}$ and $f_{2}$ for mid vowels of Galician within the different durations of the gesture tested. Circular dots represent /e/; squares represent $/ \varepsilon /$; triangles represent $/ \mathrm{o} /$; and pentagons represent $/ \mathrm{o} /$. The degree of transparency marks the duration of the gesture, with black representing greater durations of the vowel gesture and paler colours representing shorter durations.






\subsubsection{Relationship between duration and formant values}

For the vowel /e/, the results from the Linear Regression showed that there is no correlation between $f_{1}$ and duration $\left(R=.549 ; R^{2}=.301, p>.05\right)$, although a significant relation was found between $f_{2}$ and duration of the gesture $\left(R=.816 ; R^{2}=.665, p<.05\right) .{ }^{9}$

For the vowel $/ \varepsilon /$ there is no correlation between $f_{1}$ and duration $\left(R=.064 ; R^{2}=.004, p>.05\right)$, although there is a significant relation between $f$ and duration $(R=.708$; $\left.R^{2}=.501, p=.05\right)$. For the vowel /o/ there is a significant negative relation between $f_{1}$ and duration $\left(R=-.724 ; R^{2}=.524\right.$, $p<.05)$, and also a significant negative relation between $f_{2}$ and duration $\left(\mathrm{R}=-.962 ; R^{2}=.925, p=.000\right)$. This means that the vowel /o/ is higher and less centralized the greater its duration. For the vowel $/ \mathrm{J} /$, there is no significant relation between either $f_{1}$ and duration $(R=-.249$; $\left.R^{2}=.06, p<.55\right)$ or $f_{2}$ and duration $\left(R=.093 ; R^{2}=.009\right.$, $p>.05)$.

\subsubsection{Relationship between duration and distance between mid-low and mid-high vowels}

In order to test whether there is a relationship between the duration of the gesture and the overlap of the formant values for mid-low and mid-high pairs of mid vowels in Galician, a Regression Analysis with duration and distance between formant frequencies for each pair

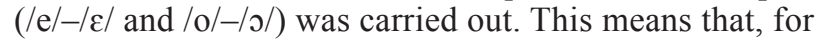
example, for the pair $/ \mathrm{e} /-/ \varepsilon /$ we calculated the Euclidean distance between the $f_{1}$ of $/ \mathrm{e} /{ }_{10}$ and the $f_{1}$ of $/ \varepsilon /{ }_{10}$, and the Euclidean distance between the $f_{2}$ of $/ \mathrm{e} /{ }_{10}$ and the $f_{2}$ of $/ \varepsilon /{ }_{10}$, and so on with every pair of mid vowels at different durations.

The results show that there is a significant linear relation between the duration of the gestures and the distance between $/ \mathrm{e} /$ and $/ \varepsilon /\left(R=.780 ; R^{2}=.609, p<.05\right)$. Furthermore, there is a significant relation between duration and the distance between $/ \mathrm{o} /$ and $/ \mathrm{o} /\left(R=.97 ; R^{2}=.94, p<.05\right)$. These results indicate that greater duration of the gesture involved in the production of the vowels is related to greater distance between mid-low and mid-high vowels, for both pairs of vowels.

\subsection{Discussion}

The results from the simulation study support the hypothesis that a greater duration of the gesture is related to a greater distinction between mid-low and mid-high vowels in both back and front pairs. However, the results do not agree completely with the hypothesis proposed.
We hypothesized that the new distinction between mid-low and mid-high vowels in word-initial position in Galician is due to the increase in the duration of the gesture in this position, making an opposition between midlow and mid-high vowels possible, since greater gesture duration results in the articulator reaching its ideal target, reducing the amount of undershoot produced at shorter durations. We expected it to be the mid-low vowels that would change depending on the gesture duration, since at short gesture durations the articulator could not achieve its articulatory mid-low target, making any acoustic distinction between mid-low and mid-high vowels impossible. However, the results obtained in this simulation study indicate that only for the mid-high vowel /o/ is there a lowering related to the decrease in the duration of the gesture, whereas the results for $/ \mathrm{J} /$ contradict our hypothesis, since there is no relation between the duration of the gesture and the formant values. This leads us to reject our expectation that it is the mid-low vowels, rather than the mid-high vowels, which changes depending on the duration of the gesture.

On the other hand, there is an unexpected relation between duration and centralization of the vowels, as shown by the results for the mid-high vowels. Although there is a significant relation between $f_{2}$ and the duration for the vowel $/ \varepsilon /$, the different behaviour between this vowel and the mid-low back /o/ leads us to consider the possibility that this significance may be due to the effect of both labialization and nasalization produced by contact with $/ \mathrm{m} /$.

Although there is ample evidence that the distance between $/ 0 /$ and $/ 0 /$ increases as duration increases, this is due to the fact that only one of them changes its formant trajectory. From this study, we may assume that, at least for $/ \mathrm{o} /$, there is movement towards the raising, and for $/ \mathrm{e} /$ and $/ \varepsilon /$ towards the extremes of the acoustical space.

In summary, we expected the mid-low vowels, and not the mid-high ones, that change depending on the duration of the gesture, but this was not supported by the results, since a relation between $f_{1}$ (taken as the acoustical cue for the vowel quality) and duration was only found for $/ \mathrm{o} /$.

\section{ACOUSTIC STUDY OF VOWELS}

\subsection{Purpose}

Since there are no acoustical descriptions of the Galician unstressed non-final vowel system, and given that the results from the first experiment were inconclusive, a second acoustic experiment was undertaken.

In this experiment, we looked at mid-low and midhigh vowels in Galician in order 1) to find out whether

\footnotetext{
${ }^{9}$ Formant values of $/ \mathrm{e} /{ }_{40}$ have been omitted from the Regression model because of their outlier values.
} 
there are acoustic differences between unstressed and stressed mid vowels as Porto Dapena (1977) and Taboada (1979) claim; those studies were not conducted from an acoustical perspective and there is still no acoustic description of unstressed vowels in Galician, so this is a necessary preliminary step; 2) to compare the quality of mid-low and mid-high unstressed vowels to see whether they differ significantly; 3 ) to find out whether there is a relationship between the duration of the segment and formant values: if there proves to be, this will allow us to explain the lowering of initial unstressed vowels as a consequence of the increase in the duration of the gesture in this position, on account of which the articulators reach their target with an improvement in quality, notwithstanding the results obtained from the simulation study.

\subsection{Methods}

\subsubsection{Stimuli and subjects}

For this study, eight native Galician speakers from any specific dialectal area were recorded, four women and four men aged from 20 to 30, all well educated.

Stimuli were designed in order to compare mid-low and mid-high vowels in both unstressed and stressed syllables. To obtain recordings that are as natural as possible, real words were chosen that exist in Galician, avoiding dialectal tokens and trying to select similar phonetic environments. In addition to stress (unstressed and stressed), we also tested the effect of the prosodic boundary condition on the production of mid vowels in order to find out if the degree of height of unstressed vowels can be related to initial position, as Porto Dapena (1977) claimed. Therefore each word was embedded in two different carrier sentences so as to observe the word in contrasting prosodic positions, following a boundary and not. The carrier sentence for the Boundary Position was " ti podes dicir sempre" (" you can always say") and the carrier sentence for the No Boundary Position was "Díxolles pausadamente" ("She told them slowly"). It is assumed that in the medial Position, the syllable of the unstressed vowel transfers the [s] of dixolles to the onset of the next token, so the unstressed vowel is not in initial position ${ }^{10}$. The variables and stimuli are presented in Table 1.

The stimuli, embedded in the carrier sentences, were presented to the speakers randomly and they were asked to read them. Each stimulus was presented in a slide separately so that speakers did not know what the next sentence would be. Every item was repeated three times along the recording.
Table 1: Stimuli used in the study to test each vowel and stress condition. Transcriptions of words in brackets.

\begin{tabular}{|c|c|c|}
\hline \multirow{2}{*}{ Vowel } & \multicolumn{2}{|c|}{ Stress } \\
\hline & Unstressed & Stressed \\
\hline /e/ & $\begin{array}{l}\text { remitir (/remi'tir/) } \\
\text { "remit [sth.]" }\end{array}$ & $\begin{array}{l}\text { xema (/'Sema/) } \\
\text { "gemstone" }\end{array}$ \\
\hline $\mid \varepsilon /$ & $\begin{array}{l}\text { emitir (/عmi'tir/) } \\
\text { "emit" }\end{array}$ & $\begin{array}{l}\text { semia (/'semja/) } \\
\text { "bran" }\end{array}$ \\
\hline $1 \mathrm{o} /$ & $\begin{array}{c}\text { comité (/komi'tz/) } \\
\text { "committee" }\end{array}$ & $\begin{array}{l}\text { pomo (/pomo/) } \\
\text { "doorknob" }\end{array}$ \\
\hline /o/ & $\begin{array}{l}\text { omitir (/omi'tir/) } \\
\text { "omit" }\end{array}$ & $\begin{array}{l}\text { toma (/'toma/) } \\
\text { "intake" }\end{array}$ \\
\hline
\end{tabular}

\subsubsection{Data collection}

Recordings were made individually, in a sound attenuated room, using a dynamic supercardioid (polar pattern), with XLR connector, model AKG D88, connected to a USB interface, model TASKAM US 122 MKII. The program Adobe Audition CS6, with a sampling rate of $44.1 \mathrm{kHz}, 32$-bit resolution, was used to obtain the recordings.

Every single vowel was manually segmented, attending to both waveform and spectrogram. Duration and formant values were taken into account. Both $f_{1}$ and $f_{2}$ were measured at the middle of the vowel, since this part is less influenced by transitions. The entire segmentation and measuring process was carried out in Praat.

\subsubsection{Data analysis}

In order to achieve the three goals of this experiment, three statistical analyses were performed using SPSS Statistics 20. The first was a General Lineal Model (GLM) Univariate Analysis to compare unstressed and stressed vowels. Since the second objective was to compare midlow and mid-high unstressed vowels, a second GLM Univariate Analysis was carried out for each /e/-/E/ and /o//o/ pair.

For those two analyses, fixed factors were Stress (Stressed and Unstressed) and Position (Boundary, No Boundary) and random factors were Speaker, with eight different levels, one for each speaker, and Sex (Women, Men); the dependent variables were $f_{1}, f_{2}$ and Duration. Post hoc comparisons of factor levels were made using Tukey HSD test with a significance level of .05.

Since our hypothesis is that there is a relationship between the duration and the quality of mid vowels, since

\footnotetext{
10 Notwithstanding recent studies that question whether resyllabification of final /s/ between prosodic groups takes place in Spanish (Strycharczuk \& Kohlberger, 2016), the behaviour of this final /s/ in boundaries between prosodic groups in Galician seems to suggest that, at least in Galician, resyllabification does occur (Fernández Rei, 2002, pp. 60-62). However, it would be best to take into the possibility of the existence of resyllabification of final /s/ in Galician, by improving the design of the carrier sentences and the selection of stimuli in future studies.
} 
one of the objectives is to test for a relationship between the duration of the segment and vowel quality, and given our intention to compare the results of native speakers with those from the simulation study, a single Linear Regression analysis was performed for both formants $\left(f_{1}\right.$ and $f_{2}$ ) and Duration for each vowel.

\subsection{Results}

The box plots in Figures 2 and 3 show the mean formant values for the four vowels studied in both Stressed and Unstressed syllables. Figure 2 shows that all the vowels studied have higher values of $f_{1}$ in Stressed than in Unstressed syllables. There also seems to be more variability in the quality of Unstressed mid-low vowels. Contrary to expectation, for the mid-high front vowel /e/ there appear to be no important differences between Stressed and Unstressed Position.

The second box plot (Figure 3) shows that mid-high vowels are more centralized in Unstressed than in Stressed syllable, since for front mid-high /e/ the mean values for $f_{2}$ are higher when Stressed than Unstressed, and for back mid-high /o/ the mean values for $f$ are lower in the Stressed than the Unstressed syllable. The reverse situation is found for mid-low vowels, which are more centralized in the Stressed syllable than in the Unstressed syllable, since for front mid-low $/ \varepsilon /$ the mean values for $f_{2}$ are lowest in the Stressed syllable, and for back mid-low $/ \mathrm{s} /$ the mean values for $f_{2}$ are higher in the Stressed syllable.

The third box plot (Figure 4) shows that there is ample variability in the Duration of vowels, especially for Unstressed mid-low vowels. However, this variability might be due to differences among speakers.

\subsubsection{Differences between Unstressed and Stressed vowels}

The results obtained from the GLM Univariate Analysis for the variables $f_{1}, f_{2}$ and Duration and the three factors tested (Stress, Position and Sex) for each vowel studied $(/ \mathrm{e} /, / \varepsilon /, / \mathrm{o} /$ and $/ \mathrm{o} /)$ are presented in Table 2.

For the vowel $/ \mathrm{e} /, f_{1}$ showed a significant effect of Stress $(F=34.303, p<.05)$. Post hoc analyses showed that the Stressed group has higher values of $f_{1}$ than the Unstressed group. This means that Unstressed /e/ is higher than Stressed /e/.

For $f_{2}$ there was a significant effect of Stress $(F=12.149, p<.05)$ and Sex $(F=49.413, p<.05)$. Post hoc comparisons showed that the Unstressed group had a significant lower $f_{2}$ than Stressed /e/. This means that Unstressed /e/ is more centralized than Stressed /e/.

Differences between Men and Women are related to the physical differences between male and female voices. For Duration there was a significant effect of Stress $(F=24.781, p<.05)$. Post hoc comparisons showed that the Stressed group had significantly greater durations than the Unstressed group.
Figure 2: Box plots for $f_{1}$ of the four vowels studied, in Unstressed and Stressed syllables.

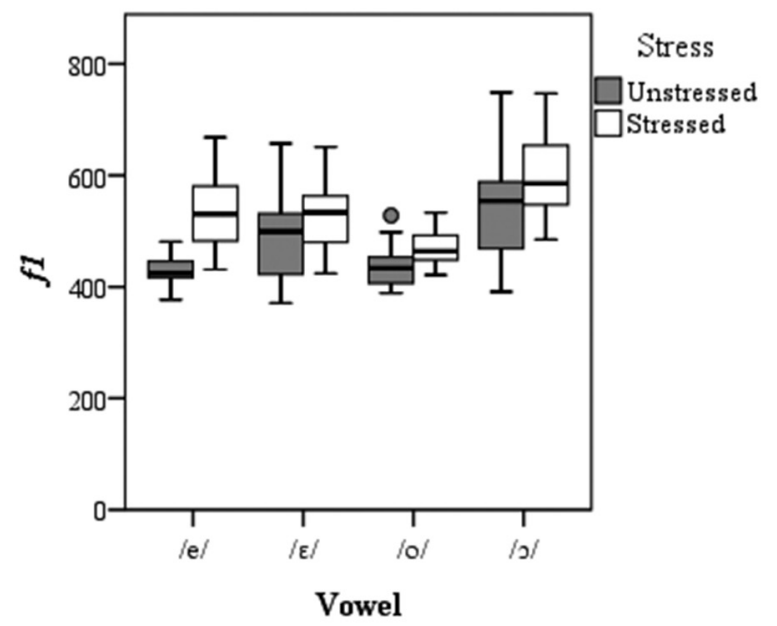

Figure 3: Box plots for $f_{2}$ of the four vowels studied, in Unstressed and Stressed syllables.

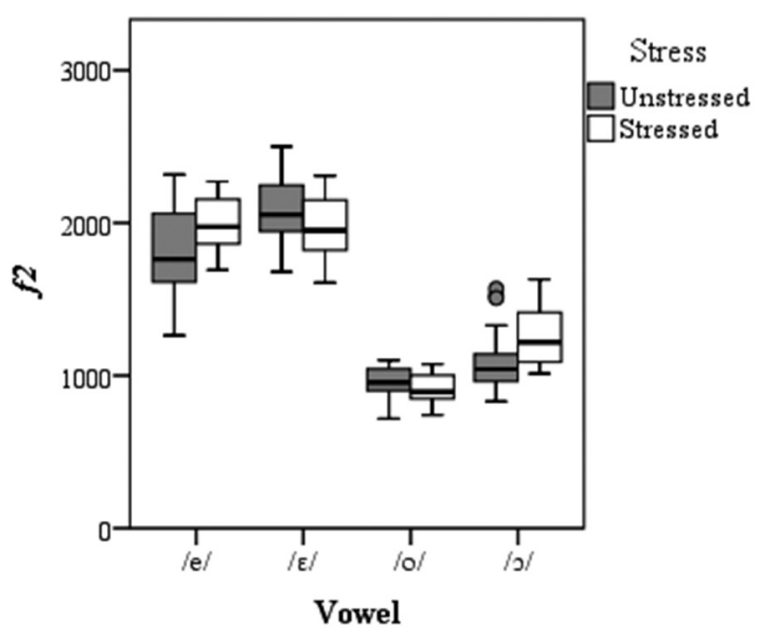

Figure 4: Box plot for the Duration of the four vowels studied, within the Stressed and Unstressed syllables.

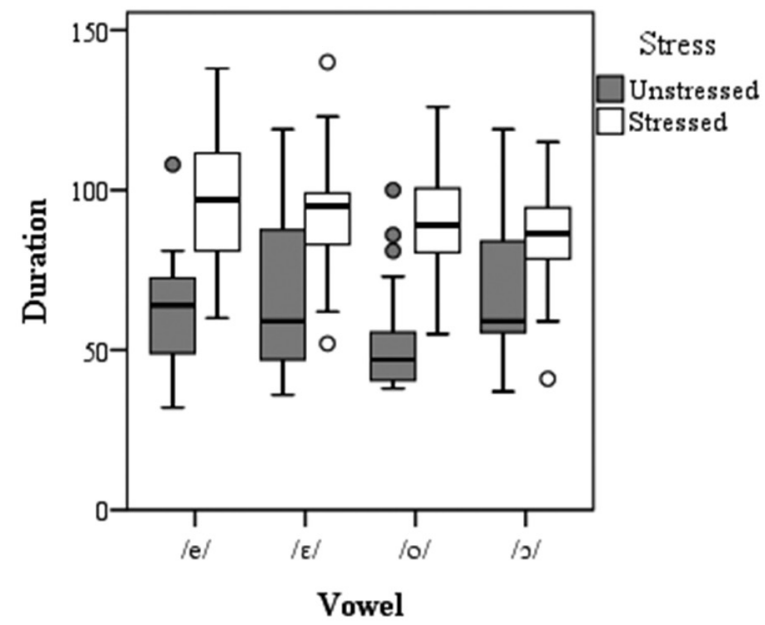


Table 2: Results obtained from the GLM Univariate Analysis for the variables $f_{1}, f_{2}$ and Duration and the three factors tested (Stress, Position and Sex) for each vowel studied (/e/, / $/, / \mathrm{o} /$ and $/ \mathrm{o} /)$. Factors with no significant effect are marked $n s ;$ otherwise, $p$ values are indicated when significant.

\begin{tabular}{|c|c|c|c|c|c|c|c|}
\hline \multirow{2}{*}{ Vowel } & \multirow{2}{*}{ Variable } & \multicolumn{2}{|c|}{ Stress } & \multicolumn{2}{|c|}{ Position } & \multicolumn{2}{|c|}{ Sex } \\
\hline & & $F$ & $p$ & $F$ & $p$ & $F$ & $p$ \\
\hline \multirow{3}{*}{$/ \mathrm{e} /$} & $f_{1}$ & 34.303 & .000 & .837 & $n s$ & 1.027 & $n s$ \\
\hline & $f_{2}$ & 12.149 & .002 & 1.904 & $n s$ & 49.413 & .000 \\
\hline & Duration & 24.781 & .000 & .004 & $n s$ & 3.585 & $n s$ \\
\hline \multirow{3}{*}{$\mid \varepsilon /$} & $f_{1}$ & 8.411 & .005 & .363 & $n s$ & 18.441 & .000 \\
\hline & $f_{2}$ & 4.333 & .042 & .275 & $n s$ & 17.784 & .000 \\
\hline & Duration & 27.811 & .000 & 1.082 & $n s$ & 5.108 & .028 \\
\hline \multirow{3}{*}{$/ 0 /$} & $f_{1}$ & 6.699 & .014 & .532 & $n s$ & .425 & $n s$ \\
\hline & $f_{2}$ & 4.237 & .048 & .840 & $n s$ & 5.168 & .030 \\
\hline & Duration & 39.866 & .000 & .234 & $n s$ & .234 & $n s$ \\
\hline \multirow{3}{*}{$/ \mathbf{s} /$} & $f_{1}$ & 7.804 & .007 & 1.273 & $n s$ & 29.845 & .000 \\
\hline & $f_{2}$ & 18.937 & .000 & 21.783 & .000 & 150.454 & .000 \\
\hline & Duration & 8.437 & .006 & .459 & $n s$ & .337 & $n s$ \\
\hline
\end{tabular}

For $/ \varepsilon /, f_{1}$ showed a significant effect of Stress $(F=8.411$, $p<.05)$ and $\operatorname{Sex}(F=18.441, p<.05)$. Post hoc analyses showed that the Unstressed group had a lower $f$ than the Stressed group, so Unstressed / $/$ / is higher than Stressed $\mid \varepsilon /$. There was also a significant effect of the interaction of the two factors $(F=5.560, p<.05)$. As Figures 5 and 6 show, in the Women's group there are no significant differences in height between Unstressed and Stressed $/ \varepsilon /$, while in the Men's group Unstressed $/ \varepsilon /$ is higher than Stressed $/ \varepsilon /$.

A possible explanation for this is that this difference between Men and Women is due to the coexistence of two models as described by Santamarina (1974), and that the men participating in the experiment have a more conservative unstressed vowel system as opposed to the

Figure 5: Interaction graph of Stress and Sex for $f_{1}$ in $/ \varepsilon /$.

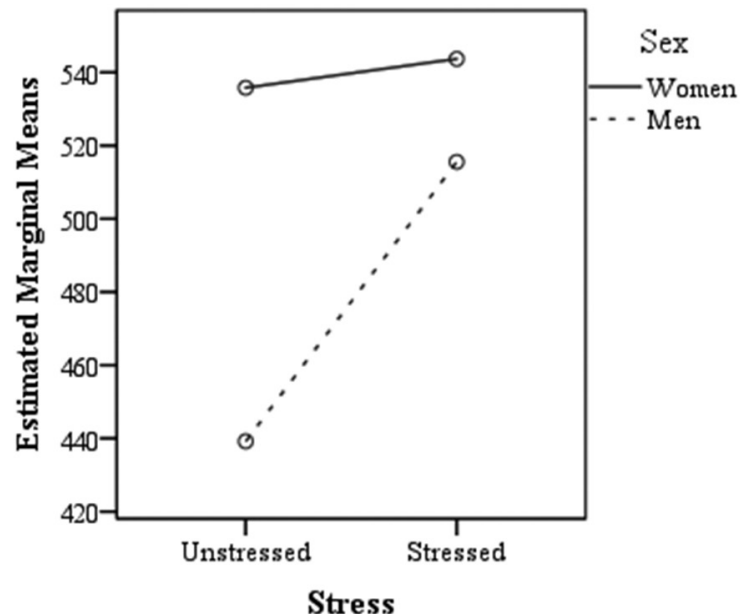

women's innovative system. However, there is insufficient evidence to back this hypothesis.

For $f_{2}$, there was a significant effect of Stress $(F=4.333$, $p<.05)$ and $\operatorname{Sex}(F=17.784, p<.05)$. Post hoc analyses showed that Unstressed $/ \varepsilon /$ had significant higher values of $f_{2}$ than Stressed $/ \varepsilon /$, which means that, unexpectedly, Stressed is more centralized than Unstressed $/ \varepsilon /$. On the other hand, the differences between Men and Women values for the $f_{2}$ are related to physical differences between female and male voices. For duration, there was a significant effect of Stress $(F=27.811, p<.05)$ and Sex $(F=5.108$, $p<.05)$. Post hoc comparisons showed that the Unstressed group had lower Duration than the Stressed one.

For the vowel /o/, the analysis showed a significant effect of Stress for $f_{1}(F=6.699, \mathrm{p}<.05)$, although there was
Figure 6: Box plot of Stress and Sex for $f_{1}$ in $/ \varepsilon /$.

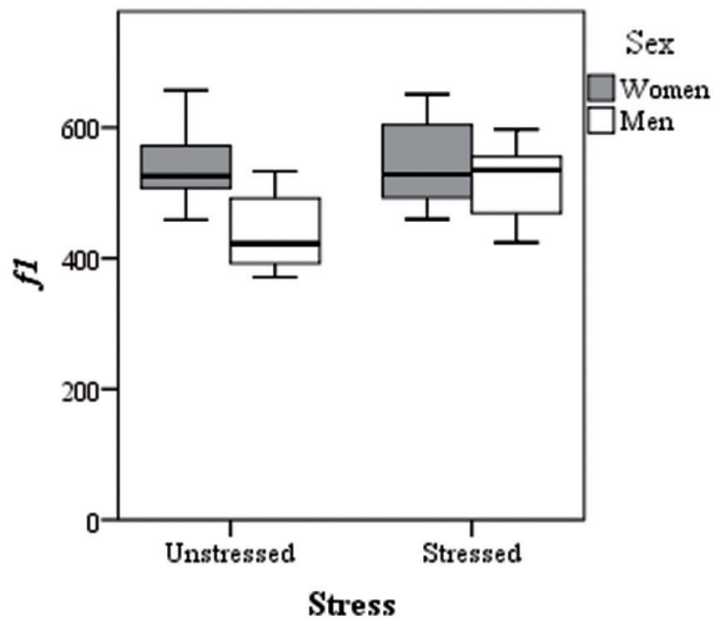


no effect of any other factor or interaction. Post hoc comparisons showed that there was a significant difference between Stressed /o/, with higher values of $f_{1}$, and Unstressed vowels. This means that Stressed /o/ is lower than the Unstressed one. For $f$ there was a significant effect of Stress $(F=4.237, p<.05)$ and $\operatorname{Sex}(F=5.168, p<.05)$, and the interaction between Stress and $\operatorname{Sex}(F=4.307, p<.05)$ was also significant, meaning that there are significant differences in the second formant values between Men and Women that are related to physiological differences.

Figures 7 and 8 show that mean values of $f_{2}$ differ between Men and Women in Stressed syllable, since $f_{2}$ in the Men's group is significant lower in Stressed than in Unstressed syllable; thus Men have a more centralized /o/ when it is Unstressed. For the Duration of $/ \mathrm{o} /$ there was a significant effect of Stress $(F=39.866, p<.05)$. Post hoc analyses showed that Stressed vowels had a significantly higher Duration than Unstressed vowels.

For $/ \mathrm{s} /, f_{1}$ shows a significant effect of both Stress $(F=7.804, p<.05)$ and $\operatorname{Sex}(F=29.845, p<.05)$. Post

Figure 7: Interaction graph of Stress and $\operatorname{Sex}$ for $f_{2}$ in /o/.

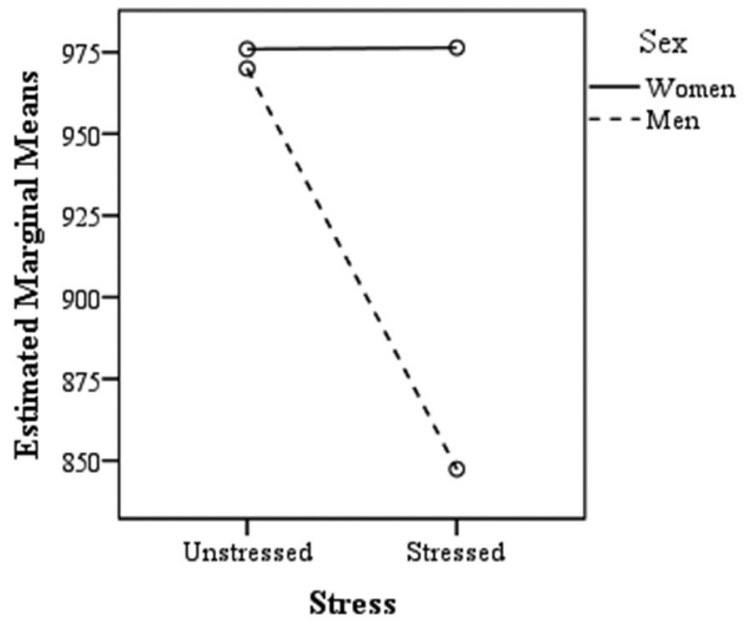

Figure 8: Box plot for $f_{2}$ in /o/ for Stress and Sex variables.

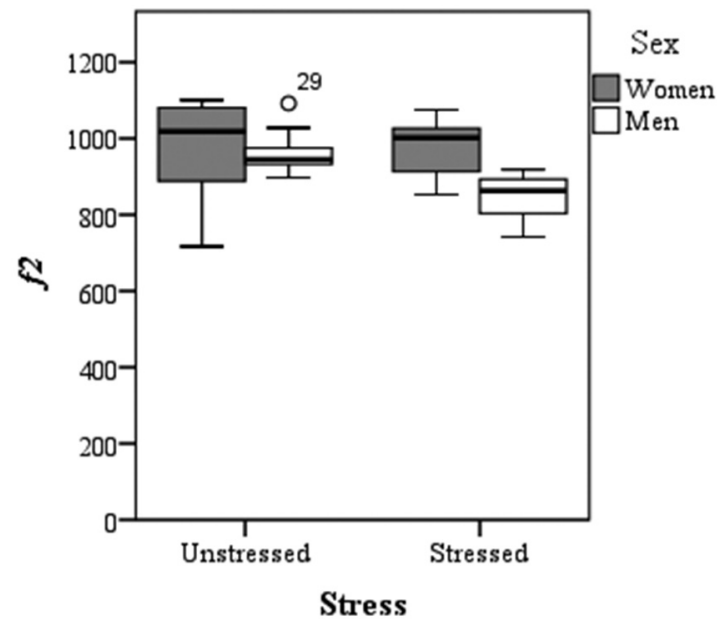

hoc analyses showed that the Unstressed group had a significant higher $f$ than the Stressed group, which means that Unstressed is lower than Stressed $/ \mathrm{O} /$.

For $f_{2}$, a significant effect of Stress $(F=18.937, p<.05)$, Position $(F=21.783, p<.05)$ and Sex $(F=150.454$, $p<.05$ ) was found, and there was also a significant effect of the interaction between Stress, Position and Sex $(F=17.333, p<.05)$. Post hoc analyses showed that the group of Unstressed vowels in Boundary Position have significantly lower $f_{2}$ than the Stressed or Unstressed group in No Boundary Position. Figures 9 and 10 show $f_{2}$ differences in Unstressed and Stressed vowels between the Boundary and No Boundary Position for Men and Women. These results indicate that, while in the Men's group there are lower values of $f_{2}$ in Unstressed / $/$, in the Women's group there is a clear difference between the Boundary and No Boundary positions for both Unstressed and Stressed $/ \mathrm{o} /$. Thus, unstressed $/ \mathrm{o} /$ has a lower $f_{2}$ in Boundary position, meaning that the vowel is less centralized than in No Boundary position.

For Duration, there was a significant effect of Stress $(F=8.437, p<.05)$. Post hoc analysis showed that the Stressed group had greater duration than the Unstressed one.

Figure 9: Interaction graphs showing the effect of the interaction between Sex (Men on the top graph, Women on the bottom one), Position and Stress on the $f_{2}$ (on the y-axis) of $/ 0 /$.
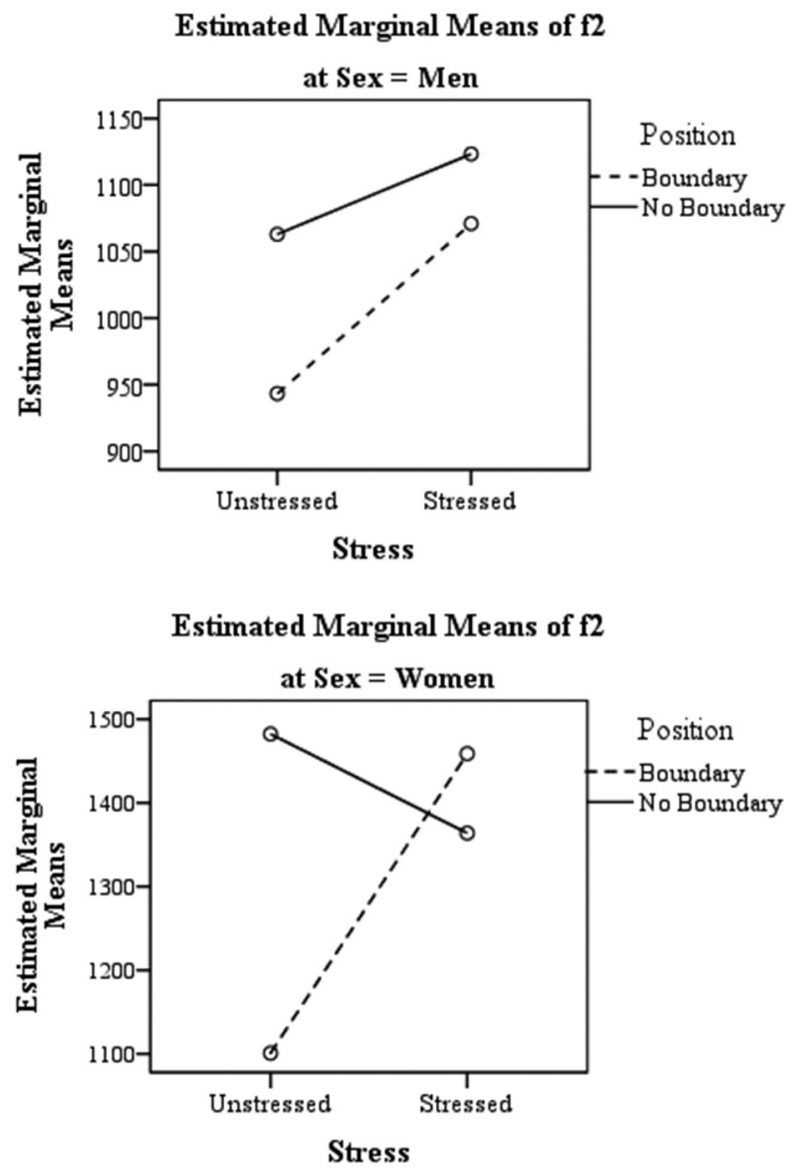


\subsubsection{Differences between mid-low and mid-high Unstressed vowels}

For the pair of mid-front vowels /e/ and $/ \varepsilon /, f_{1}$ showed a significant effect of the factors Vowel $(F=16.630$, $p<.05)$ and $\operatorname{Sex}(F=7.445, p<.05)$, and also for the interaction between Vowel and Sex $(F=14.221$, $p<.05)$. For $f$ there was a significant effect of the factors Vowel $(F=14.672, p<.05)$ and Sex $(F=27.653$, $p<.05)$. For Duration, there were no significant differences between $/ \mathrm{e} /$ and $/ \varepsilon /$. As expected, mid-low vowel $/ \varepsilon /$ has higher values of $f_{1}$ and $f$ than mid-high /e/.

For the pair of back-mid vowels $/ 0 /$ and $/ \mathrm{o} /, f_{1}$ showed a significant effect of Vowel $(F=32.449$, $p<.05)$ and $\operatorname{Sex}(F=6.128, p<.05)$, and also for the interaction between Vowel and Sex $(F=10.423$, $p<.05)$. Post hoc comparisons showed that the midlow vowel $/ \mathrm{s} /$ has significantly higher values of $f_{1}$ within the Women's group. For $f_{2}$ there was a significant effect of Vowel $(F=40.284, p<.05)$, Position $(F=26.902$, $p<.05)$, and Sex $(F=28.677, \mathrm{p}<.05)$; and there was also an effect of the interaction between Vowel and Position $(F=15.489, p<.05)$, the interaction between Vowel and Sex $(F=26.432, p<.05)$, and the interaction of all three factors $(F=7.753, p<.05)$. Post hoc comparisons showed that, within the Women's group, mid-low $/ 0 /$ has significantly higher values of $f_{2}$ in No Boundary position, which means that in this position the vowel is more centralized than in Boundary position. For Duration, there was a significant effect of Vowel $(F=9.388, p<.05)$. Post hoc comparisons showed that the mid-low back vowel is significantly longer than the mid-high back vowel.

Figure 10: Box plots for the $f_{2}$ of $/ \mathrm{s} /$ in Boundary and No Boundary Positions for Unstressed and Stressed syllables for Men (left column) and Women (right column).

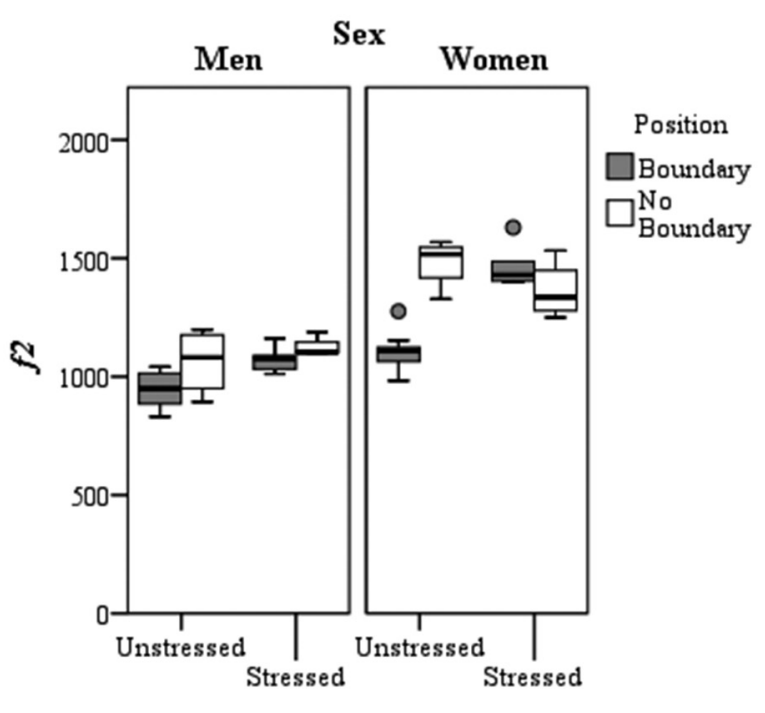

Stress

\subsubsection{Relationship between vowel quality and Duration}

In order to find out whether there is a relationship between formant values and the duration of the unstressed vowels, two Linear Regression analyses were performed for each vowel, one taking $f_{1}$ as the dependent variable and Duration as the independent variable, and the other taking $f_{2}$ as the dependent variable and Duration as the independent variable.

The results show that for the vowel /e/ there is no significant linear relation between $f_{1}$ and Duration $\left(R^{2}=.043\right.$, $F=.631, p>.05)$ or between $f_{2}$ and Duration $\left(R^{2}=.175\right.$, $F=2.963, p>.05)$. Likewise, for $/ \varepsilon /$ there is no significant linear relationship between $f_{1}$ and Duration $\left(R^{2}=.007, F=.211, p>.05\right)$, nor between $f_{2}$ and Duration $\left(R^{2}=.054, F=1.700, p>.05\right)$. And also for $/ \mathrm{o} /$ there is also no significant linear relation between $f_{1}$ and Duration $\left(R^{2}=.005, F=.102, p>.05\right)$ or between $f_{2}$ and Duration $\left(R^{2}=.023, F=.521, p>.05\right)$.

However, for $/ \mathrm{a} /$ the analysis showed a significant linear relation between $f_{1}$ and Duration $\left(R^{2}=.135\right.$, $F=4.683, p<.05)$, although there is no significant linear relation between $f_{2}$ and Duration $\left(R^{2}=.010\right.$, $F=.229, p>.05)$. This means that the greater the duration of a segment, the higher the $f_{1}$, as is seen in the scatterplot in Figure 11.

Figure 11: Scatterplot for $f_{1}$ and Duration (in $\mathrm{ms}$ ) of $/ \mathrm{o} /$.



\subsection{Discussion}

According to the results obtained from the first analysis (see section 3.3.1), we may conclude that there are significant acoustic differences, in terms of height and centralization, between Galician unstressed and stressed mid vowels, in agreement with Porto Dapena's (1977) suggestion that unstressed vowels are more unclear and variable than stressed vowels. Broadly, vowels are longer in stressed syl- 
lables than in unstressed ones. The unstressed mid-high vowels /e/ and /o/ and mid-low / $/$ / are higher and (at least for men) more centralized than their stressed counterparts. On the other hand, unstressed $/ \mathrm{o} /$ is lower and less centralized than stressed / $/$ /, except in No Boundary Position in women.

The second analysis (see section 3.3.2.) showed significant differences in the height and centralization of the unstressed mid-front pair, $/ \mathrm{e} /-/ \varepsilon /$, although there is no difference in duration. For the unstressed mid-back vowels, $/ 0 /-/ 0 /$, there are also significant differences in height and centralization, plus greater duration for $/ \mathrm{s} /$ than for $/ \mathrm{o} /$. Moreover, for unstressed $/ \mathrm{s} /$ there is a significant effect of position on $f_{2}$ values, which means that this vowel is more centralized in medial position than in initial boundary position in women. On the other hand, the third analysis (see section 3.3.3) showed a significant relation between duration and height of the unstressed low mid-back vowel $/ \mathrm{o} /$. Although the existence of a significant relation does not imply causality, this significance supports our hypothesis.

We can assume that most of the effects of the sex variable can be explained as physiological differences between male and female voices as Harrington (2010) states,

the formants of the female speaker are higher in frequency than those of the male, which is expected because female vocal tracts are on average shorter. But, as argued in Fant (1966), because the ratio of the mouth cavity to the pharyngeal cavity lengths is different in male and female speakers, the changes to the vowels due to gender are non-uniform: this means that the male-female differences are greater in some vowels than others. . . . Also the F2 differences are much more marked than those in F1 (p. 184).
However, it seems that for unstressed mid-low vowels the results point to the continued coexistence of the two models described by Santamarina (1974), one of which is more conservative, represented in this study by the men's group, and the other more innovative, represented by the women's group. Those results can be seen in the scatterplots in Figure 12.

\section{DISCUSSION}

The articulatory study conducted using TADA has shown that from an articulatory point of view there is a clear relation between the duration of the gesture and the height of the vowel. However, this relation has been verified only for the mid-high vowels, which diverge from our hypothesis that it is the low-mid vowels, and not the high-mid ones, that change depending on the duration of the gesture.

Despite this, the simulation study gives ample evidence that shorter duration of the gesture produces more centralized vowels, and longer durations favour the distinction between mid-low and mid-high vowels.

However, the results from the simulation study do not agree with those from the acoustic study. The second experiment confirmed that there is a significant relation between duration and height for $/ \mathrm{s} /$, a result which supports our initial hypothesis.

On the other hand, the initial position of unstressed mid-low vowels does not seem to be related either to height or to vowel duration, contrary to the hypothesis that the position of the syllable accounts for the change discussed. This suggests that the lowering of unstressed vowels may be triggered by vowel duration, as implied by the results for unstressed $/ \mathrm{\rho} /$, but it

Figure 12: Scatterplots of the mean formant values for the four vowels within two different kind of syllable. The circle represents the vowel /e/; the square represents $/ \varepsilon /$; the triangle represents $/ \mathrm{o} /$; the pentagon represents $/ 0 /$. Grey markers represent stressed vowels, and black markers represent unstressed vowels.

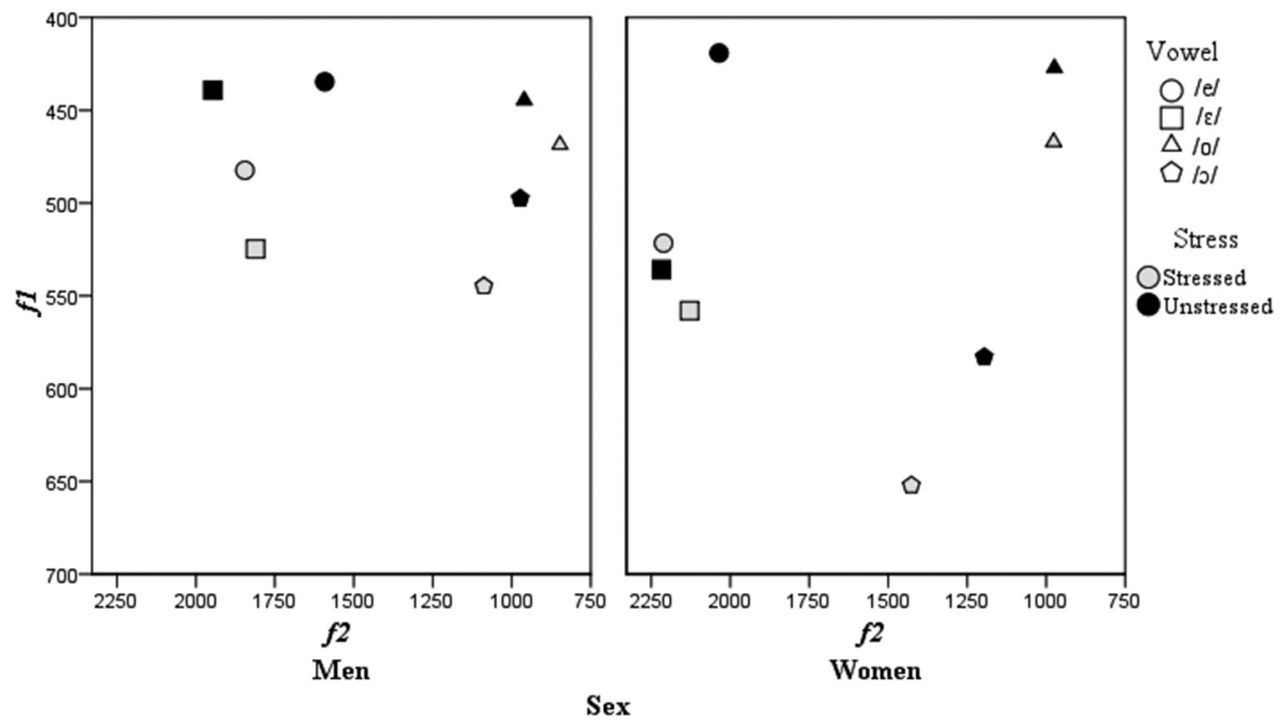


cannot be assumed that either greater duration or lowering are triggered by the initial syllable structure. However, this may be due to defects in the experimental design related to the stimuli and carrier sentences selected. Therefore, these results should be treated with caution.

The results suggest that this change is still operating, in view of the coexistence of two models and the variation in the height of mid-low unstressed vowels.

Even though there is no relation between syllable position and height, it was found that the initial boundary condition is nevertheless related to less centralization of $/ \mathrm{s} /$. It would be interesting to explore this issue further in a future study.

\section{CONCLUSION}

The aim of this study was to examine a recent change in the Galician unstressed vowel system, where a new distinction has arisen for mid vowels, specifically between mid-front $(/ \mathrm{e} /-/ \varepsilon /)$ and mid-back $(/ \mathrm{o} /-/ \mathrm{o} /)$ vowels. This study focuses on this change when the vowel is in initial position.

The hypothesis adopted proposes that this change is triggered by an increase in the duration of the vowel gesture (on account of the vowel's position in initial position), since a greater duration would allow the articulator to achieve any ideal target, giving rise to a new distinction between mid-low and mid-high vowel targets.

To test this hypothesis, a simulation experiment and an acoustical study were carried out. The simulation experiment within the articulatory model of TADA allowed us to find out whether there is a relation between the duration of the gesture and the height of the vowel. The aim of the acoustic study was to find out whether there is a relation between the duration and the height of unstressed mid vowels, and whether this may be triggered by the specific structure of the syllable in initial position. This acoustic study also provided the first acoustic description of the unstressed non-final vowel system of Galician.

In summary, this study shows that, for each mid-low vowel in Galician, there are significant acoustic differences between unstressed and stressed vowels, as Taboada (1979) and Porto Dapena (1977) had predicted several decades ago. It also found significant differences between mid-low and mid-high vowels for each unstressed pair.

The evidence from the simulation study with TADA supports the hypothesis that a greater distinction between mid-low and mid-high unstressed vowels is related to longer duration of the gesture. However, the increase in distinction is caused by the mid-high vowels, since there is no evidence for a relation between duration and height for mid-low vowels.

Nevertheless, the results of the acoustic study indicate that the height of the low mid-back vowel is related to its duration. Therefore, this study leads us to the conclusion that there is a relation between vowel duration and the acoustic height of the vowel, even though the results of the simulation experiment do not coincide with those from the acoustic study. A relation between vowel duration and the distance between mid-low and mid-high vowels was also confirmed. However, we cannot assume either greater duration or height to be triggered by a syllable structure without onset or coda, nor to the word-initial position.

However, as pointed out in Section 4, since this is a preliminary study and some experimental points present methodological problems (such as the stimuli selected and control of the prosodic variable), the results obtained in this study should be treated with caution.

Moreover, the results from the acoustic study suggest that the change discussed here is still in progress, since two different models, an innovative model and a conservative one, operate side-by-side.

It would be interesting to compare the data from this experiment with Portuguese, since its vowel system is close to Galician, as has been shown by Nobre and Ingemann (1983): "Brazilian Portuguese is normally analyzed as having three different phonemic oral vowel sets depending on location of stress: /i e $\varepsilon$ a $\supset$ o $\mathrm{u} /$ in stressed position, /i e $ə$ o $\mathrm{u} /$ before stressed syllables, and /i $ə \mathrm{u} / \mathrm{in}$ unstressed word-final position" (p. 1).

The possibility that the centralization generally described for Portuguese might be related to shorter gesture duration is supported by the results obtained in our simulation study. Our results broadly agree with those presented by Nobre and Ingemann (1983); they state that, for some dialects of Brazilian Portuguese:

Mean F1 frequencies of pretonic vowels are at a point halfway between those of adjacent vowels, which corresponds to a lowering of the higher vowels $[\mathrm{i}, \mathrm{e}, \mathrm{o}, \mathrm{u}]$ and a raising of the lower vowels $[\varepsilon, \mathrm{a}, \mathrm{o}]$.

Mean F2 frequencies of the pretonic vowels [e, ə, o, $\mathrm{u}]$ all indicate centralizing tendencies, with the back vowels exhibiting more centralization than [e] (p. 4).

For duration they found the same behaviour, since stressed vowels are longer than unstressed vowels. In any case, Brazilian Portuguese has no phonological distinction between mid-low and mid-high vowels in unstressed position, with the preference for one realization or the other depending on dialect area. Also, it has been noted (Emiliano, 2009) that the mid-high realization of unstressed vowels connotes a prestige variety of Portuguese, since it is the common realization in standard European Portuguese.

Thus, another possible explanation for the results obtained in this study is that the inter-speaker variation is due to dialectal preferences, as in Brazilian Portuguese, or to the effect of any prestige variety. It would be interesting to go further on the study of these and other hypotheses in future investigations. 


\section{ACKNOWLEDGMENTS}

This work was partially supported by the Ministerio de Educación, Cultura y Deporte (under the grant FPU 13/06568). I am very grateful to the participants for their contribution. I would like to express my gratitude to Elisa Fernández Rei, Benjamin Parrell, Xosé Luís Regueira, two anonymous reviewers and the editors for the many useful comments, suggestions and corrections, which have undoubtedly improved the paper. All mistakes that remain in the text are mine.

\section{REFERENCES}

Browman, C.P., \& Goldstein, L. (1993). Dynamics and Articulatory Phonology. Haskins Laboratories Status Report on Speech Research, SR 113, 51-62. Retrieved from http://web.haskins.yale. edu/sr/sr113/SR113 04.pdf.

Fant, G. (1966). A note on vocal tract size factors and non-uniform F-pattern scaling. Speech Transmission Laboratory, Quarterly Progress Status Reports, 4, 22-30.

Fernández Rei, E. (2002). Regras fonolóxicas posléxicas e regras precompiladas de alomorfia sintagmática: dominios prosódicos en galego. Santiago de Compostela: Universidade de Santiago de Compostela.

Goldstein, L., Chitoran, I., \& Selkirk, E. (2007). Syllable structure as coupled oscillator modes: Evidence from Georgian and Tashlhiyt Berber. In J. Trouvain, J., \& Barry, W.J. (Eds.), Proceedings of the 16th International Congress of Phonetic Sciences (ICPhS '07), 241-244.

Harrington, J. (2010). Phonetic analysis of speech corpora. Chichester: Wiley-Blackwell.

Haskins Laboratories (2001-2006). TADA (Task Dynamics Application), version 0.9782 . Retrieved from http://www.haskins.yale. edu/tada_download/index.php.

Hawkins, S. (1992). An introduction to task dynamics. In G.J. Docherty \& D.R. Ladd (Eds.), Papers in laboratory phonology II: Gesture, segment, prosody (pp. 9-25). Cambridge: Cambridge University Press. http://dx.doi.org/10.1017/CBO9780511519918.002.

Lausberg, H. (1971). Linguistica Romanza. I: Fonetica. (N. Pasero, Trans.). Milano: Feltrinelli.

Nam, H., \& Goldstein, L. (2007). TADA (Task Dynamics Application) manual. Haskins Laboratories. Retrieved from http://sail.usc. edu/ lgoldste/ArtPhon/TADA\%20stuff/TADA manual v09.pdf

Nobre, M.A., \& Ingemann, F. (1983). [Reprinted 1992]. Oral vowel reduction in Brazilian Portuguese. Kansas Working Papers, 8(1), 1-30.

Porto Dapena, J.A. (1977). El gallego hablado en la comarca ferrolana. Verba. Anuario Galego de Filoloxía, Anexo 9. Santiago de Compostela: Servizo de Publicacións da Universidade de Santiago de Compostela.

Regueira, X.L. (2008). Cambios fonolóxicos no galego actual. In Brea López, M., Fernández Rei, F., \& Regueira Fernández, X.L. (Coords.), Cada palabra pesaba, cada palabra medía. Homenaxe a Antón Santamarina. Santiago de Compostela: Servizo de Publicacións e Intercambio Científico da Universidade de Santiago de Compostela, 275-286.

Regueira, X.L. (2009). Cambios fonéticos e fonolóxicos no galego contemporáneo. Estudos de Lingüística Galega, 1, 147-167. http://dx.doi.org/10.3309/1989-578X-09-8.

Regueira, X.L. (Dir.). (2010). Dicionario de pronuncia da lingua galega. Santiago de Compostela: Instituto da Lingua Galega. Retrieved from http://ilg.usc.es/pronuncia.

Santamarina, A. (1974). El Verbo gallego: estudio basado en el habla del Valle del Suarna. Verba: Anuario Galego de Filoloxía. Santiago de Compostela: Universidad de Santiago de Compostela. Servizo de Publicacións e Intercambio Científico.

Strycharczuk, P., \& Kohlberger, M. (2016). Resyllabification reconsidered: On the durational properties of word-final/s/ in Spanish. Laboratory Phonology: Journal of the Association for Laboratory Phonology, 7(1), 3. http://dx.doi.org/10.5334/labphon.5.

Sensimetrics Corporation (2009). HLSync. Retrieved from http:// www.sens.com/

Taboada, M. (1979). El habla del Valle de Verín. Verba. Anuario Galego de Filoloxía, Anejo 15, Universidade de Santiago de Compostela: Servizo de Publicacións da Universidade de Santiago de Compostela.

Veiga Arias, A. (1965). Fonología gallega. Fonemática: el sistema vocálico. Grial, 10, 390-403. 